\title{
$\mathfrak{W e g} \mathfrak{e f i l d} \mathfrak{e} \mathfrak{e r}$
}

in Das

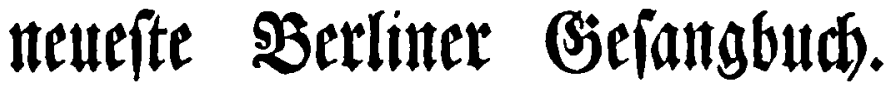

\section{Nadjolagewert,}

uIII füt jede Art driftlid)er Betrad)tungen gemápe

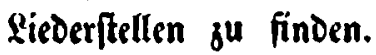

Sanbreidung aud bem ungelebrten.

\section{Enthalteno:}

A. Inbalt bee Befangbudbs, biz ins Cinzelne nubgefübrt; Sinberlisoer 2 .

B. Iretobien = Regifter.

C. Sieber, bie mit ben Sonn unb Feftagb = Evangelien und Epifteln úbercintommen.

D. Uugemeines \$ort $=$ und Gad $=$ Regifter.

Berlin bei $\mathbb{B}$. Reimer.

1834. 
